\title{
A NEW METHOD OF DISTINGUISHING BUTTER FROM SOME OTHER
} FATS.

By William Gustavus Crook, Public Analyst for Norwich.

Haviva been lately specially engaged in examining several kinds of fat for the purpose of identification, I will, as briefly as I am able, describe a method arrived at, which will in a few minutes distinguish butter from the fat of beef, mutton, or pork, or mixtures of them. The sample to be examined (if in the form of butter) must be first melted and rendered pretty free from water and salt, by filtration if necessary; ten grains are then to be put into a test tube, and liquified by placing the tube in hot water at about $150^{\circ} \mathrm{F}$.; remove the tube when ready, and add thirty minims of carbolic acid (Calvert's No. 2 acid, in crystals, one pound; distilled water, two fluid ounces). Shake the mixture, and again place it in the water-bath until it is transparent. Set the tube aside for a time. If the sample thus treated be pure butter, a perfect solution will be the result; if beef, mutton, or pork fat, the mixture will 
resolve itself into two solutions of different densities, with a clear line of demarcation : the denser of the two solutions, if beef fat, will occupy about 49.7 ; lard, 49.6 ; mutton, 44.00 per cent. of the entire volume; when sufficiently cooled, more or less deposit will be observed in the uppermost solution. If olive oil be thus tested, the substratum will occupy about 50 per cent.; with castor oil, there is no separation. With some solid fats (not likely to be used fraudulently) no separation whatever takes place; the addition of a minute portion of alkanet root will render the reading of the scale extremely distinct by artificial light. The above method (although not intended to surpass other processes) is capable of wide application, the saving of a large amount of time, and the reliability of its results will at once recommend it as a "first step" in butter analysis. 